(1)

CrossMark

\title{
The search for the hypersensitivity in chronic cough
}

\author{
Surinder S. Birring
}

Affiliation: King's College London, Division of Asthma, Allergy and Lung Biology, London, UK.

Correspondence: Surinder S. Birring, King's College London, Division of Asthma, Allergy and Lung Biology, Denmark Hill, London SE9 5RS, UK. E-mail: surinder.birringanhs.net

@ERSpublications

ATP activation of $\mathrm{P} 2 \mathrm{X} 3$ receptors: an important mechanism in cough but does it underlie the hypersensitivity? http://ow.ly/TNNZ308bu2a

Cite this article as: Birring SS. The search for the hypersensitivity in chronic cough. Eur Respir J 2017; 49: 1700082 [https://doi.org/10.1183/13993003.00082-2017].

Chronic cough is a common disorder that affects an estimated $10 \%$ of the general population [1]. Adverse symptoms such as urinary incontinence, chest pains, headaches and syncope are frequently associated with cough and lead to poor health-related quality of life $[2,3]$. Chronic cough has long been viewed as a symptom of other chronic disorders, hence the current approach to assessing and treating patients focuses on identifying an underlying condition, such as asthma and gastro-oesophageal reflux disease [4]. A significant number of cases of chronic cough, as many as 50\%, remain unexplained following detailed assessment. They are often referred to as idiopathic, unexplained or refractory chronic cough $[5,6]$. Recently, there has been consensus that chronic cough is a disorder of dysregulated sensory nerves and the associated central processing [7]. In this model, an important symptom reported by patients is an exaggerated sensation of the urge to cough, reflecting a disorder of the primary ascending neurons that innervate the airways and lungs [8]. Cough nerve endings are part of a larger visceral sensory nervous system that communicates information about the local environment via the vagus nerve to the central nervous system [8]. The trigger for cough is often a peripheral stimulation of the airways. Chemical and mechanical stimuli can activate the airway afferent nerves, for example changes in osmolarity, temperature, $\mathrm{pH}$ and environmental irritants in the air that we breathe [8]. Patients with chronic cough, compared to healthy subjects are hypersensitive to a wide range of inhaled tussive agents. Examples include capsaicin, citric acid and fog, and their use to induce cough is the basis of the cough challenge test, widely used in research [9]. The peripheral stimulus can activate a brain stem mediated reflex-cough or, more often, a sensation associated with airway irritation (urge to cough) that promotes a behavioural or voluntary cough to relieve this [8].

The term "cough hypersensitivity syndrome" (CHS) for chronic cough disorders has been proposed by a European Respiratory Society task force $[7,10]$. This recognises the important role of dysregulated sensory nerves and is supported by a number of observations.

1) The profile of symptoms in patients with CHS is similar to neuropathic disorders such as pain in which patients experience exaggerated pain to painful stimuli (hyperalgesia) and non-painful stimuli (allodynia). CHS patients frequently report exaggerated coughing to known tussive stimuli, for example, strong odours and smoke (hypertussia) and to non-tussive stimuli such as talking and laughing (allotussia). Abnormal sensations in the throat, such as a tickle (laryngeal paraesthesia), occur frequently. One study reported this to be present in $94 \%$ of patients [11].

Received: Jan 132017 | Accepted: Jan 162017

Conflict of interest: Disclosures can be found alongside this article at erj.ersjournals.com

Copyright OERS 2017 
2) Neuropeptides, released from sensory nerves can act as neurotransmitters and initiate local inflammatory responses. They are present in increased concentrations in the airways of patients with cough $[12,13]$.

3) Recent functional magnetic resonance imaging studies have reported increased activation in the cortical and subcortical brain centres of patients with cough, that integrate the intensity and location of the cough stimulus, as well as providing a descending motor pathway that can promote or inhibit the act of coughing [14].

4) Neuromodulator therapies such as gabapentin, pregabalin and amitryptyline are effective in some patients with cough [15-17]. Behavioural therapies as part of physiotherapy or speech therapy interventions are also effective in reducing the frequency of cough and improving quality of life [18, 19]. It is important to note that while there is consensus for neuronal dysfunction in cough, there is a paucity of studies that have provided direct evidence to support this. It has been difficult to study pulmonary sensory nerves and their function in patients and the exact mechanism of cough hypersensitivity remains elusive. The sensory nerves and their receptors in the airways of patients with cough have only recently been visualised and further studies are needed to investigate their structure and function and the relationship with clinical measures of cough hypersensitivity [20].

In the 1950s, adenosine 5'-triphosphate (ATP) emerged as an important sensory nerve neurotransmitter but it was not until the 1990s that ATP receptors were identified and cloned [21, 22]. ATP is released from a wide range of cells, including the airway epithelium. The amount released increases in response to inflammation and mechanical stress [23]. The effects of extracellular ATP are mediated by a number of cell surface P2 purinergic receptors [23]. The P2X3 receptor, whose expression is largely limited to sensory nerves, has recently emerged as being highly relevant to cough [23]. Treatment with MK7264 (formerly AF219), an antagonist of the P2X3 receptor, was associated with a striking reduction in the frequency of cough in a randomised controlled trial of patients with CHS [24]. This discovery is exciting from a therapeutic point of view because it is potentially a new class of pharmacotherapy for the relief of troublesome symptoms in patients with chronic respiratory disease. It also has the potential to treat large numbers of patients across a wide spectrum of respiratory disorders. It is also exciting from a mechanistic point of view as the antitussive effect of MK7264 raises the possibility that the cough reflex hypersensitivity in CHS is due to ATP activation of purinergic receptors.

If this is the case then it should be possible to demonstrate a heightened tussive response to ATP unique to patients with CHS compared to healthy subjects. The study by FowLes et al. [25] in this issue of the European Respiratory Journal investigated the hypothesis that ATP activation of P2 purinergic receptors underlies the cough hypersensitivity in CHS. They compared the tussive response to inhaled ATP between patients with CHS and healthy subjects. They found inhalation of ATP caused cough in both groups, confirming the findings of previous studies [26]. They report for the first time that patients with CHS have heightened sensitivity to ATP compared to healthy subjects. This suggests that ATP activation of the P2X3 receptor is an important mechanism in CHS. A closer examination of their findings however reveals the heightened sensitivity to inhaled ATP was not sufficiently unique to CHS. There was significant overlap in the tussive response to ATP between patients with CHS and healthy subjects. This finding is similar to those with other tussive agents used in cough challenge tests, such as capsaicin [9]. FowLes et al. [25] had to conclude that patients with CHS do not have an intrinsically heightened sensitivity to ATP. One explanation is that the key site of neuronal dysfunction is downstream of airway peripheral nerve endings, such as the nerve cell body or in the brain. If this is true, then the cough challenge test may not be the appropriate investigation, since inhaled ATP probably activates receptors upstream, located on airway peripheral nerve endings. In some patients, central sensitisation and loss of inhibitory cortical activity may be important in the development of CHS [8]. There are a number of effective therapies that support a key role of central neural pathways in CHS. Gabapentin, pregabalin and amitriptyline are good examples [15]. Speech and physiotherapy cough reduction therapies are also effective; they include cough suppression and distraction techniques and behaviour modification to consciously control cough $[18,19]$. It is also worth noting that the peripherally acting therapy MK7264 is not effective in some patients and does not supress cough completely to the levels of healthy subjects [23, 24]. The key site of neuronal dysfunction may therefore be central in some patients. It is possible that the wide range of the sensitivity to ATP may be due to its biological characteristics; it is rapidly broken down, its breakdown products may be active, it activates receptors other than the P2X3, and the presence of physiological levels of ATP may alter the response to that administered exogenously. Lastly, and perhaps most importantly, CHS is likely to be more complex than the up-regulation of a single receptor. Several neuro-phenotypes of CHS have been proposed that include exaggerated tussive responses mediated via a number of neuronal receptors that include transient receptor potential ankyrin-1 (TRPA1), vanilloid-4 (TRPV4) and neurokinin-1 [27, 28]. Further study of these targets may yield important insights into the mechanism of CHS. An important limitation of cough challenge tests, such as the one used by Fowles et al. [25] needs to be acknowledged. They 
assessed the cough motor response to inhaled ATP, C5, the concentration of tussive agent that causes five or more coughs. This may be a poor indicator of sensory nerve dysfunction since it measures the motor response to a stimulus. The sensation "urge to cough" and the ability to suppress cough may better reflect sensory nerve activation and impaired inhibitory control. This therefore should be assessed during cough challenge tests in future. The potential of assessing urge to cough and cough suppression as diagnostic tests for CHS should also be investigated [29-31].

CHS is a disorder gaining increasing recognition amongst respiratory, allergy, gastroenterology, speech/ voice and otolaryngology healthcare professionals. A better understanding of the sensory nerve dysfunction has led to the development of a number of treatments. There are therapies currently in clinical trials that target sensory nerves. The study from Fowles et al. [25] yields important insights into the mechanisms that underlie CHS. Further studies should investigate any genetic predisposition to developing CHS, determine the triggers of CHS and identify the peripheral and central nerves and their receptors involved in maintaining the hypersensitivity.

\section{References}

1 Song WJ, Chang YS, Faruqi S, et al. The global epidemiology of chronic cough in adults: a systematic review and meta-analysis. Eur Respir J 2015; 45: 1479-1481.

2 Brignall K, Jayaraman B, Birring SS. Quality of life and psychosocial aspects of cough. Lung 2008; 186: Suppl. 1, S55-S58.

3 Birring SS, Prudon B, Carr AJ, et al. Development of a symptom specific health status measure for patients with chronic cough: Leicester Cough Questionnaire (LCQ). Thorax 2003; 58: 339-343.

4 Morice AH, Fontana GA, Sovijarvi AR, et al. The diagnosis and management of chronic cough. Eur Respir J 2004; 24: 481-492.

5 Haque RA, Usmani OS, Barnes PJ. Chronic idiopathic cough: a discrete clinical entity? Chest 2005; 127: $1710-1713$.

6 Birring SS, Brightling CE, Symon FA, et al. Idiopathic chronic cough: association with organ specific autoimmune disease and bronchoalveolar lymphocytosis. Thorax 2003; 58: 1066-1070.

7 Morice AH, Millqvist E, Belvisi MG, et al. Expert opinion on the cough hypersensitivity syndrome in respiratory medicine. Eur Respir J 2014; 44: 1132-1148.

8 Mazzone SB, Undem BJ. Vagal afferent innervation of the airways in health and disease. Physiol Rev 2016; 96: 975-1024.

9 Prudon B, Birring SS, Vara DD, et al. Cough and glottic-stop reflex sensitivity in health and disease. Chest 2005; 127: 550-557.

10 Birring SS. Developing antitussives: the ideal clinical trial. Pulm Pharmacol Ther 2009; 22: 155-158.

11 Vertigan AE, Gibson PG. Chronic refractory cough as a sensory neuropathy: evidence from a reinterpretation of cough triggers. J Voice 2011; 25: 596-601.

12 Hope-Gill BD, Hilldrup S, Davies C, et al. A study of the cough reflex in idiopathic pulmonary fibrosis. Am J Respir Crit Care Med 2003; 168: 995-1002.

13 Otsuka K, Niimi A, Matsumoto H, et al. Plasma substance P levels in patients with persistent cough. Respiration 2011; 82: 431-438.

14 Ando A, Smallwood D, McMahon M, et al. Neural correlates of cough hypersensitivity in humans: evidence for central sensitisation and dysfunctional inhibitory control. Thorax 2016; 71: 323-329.

15 Ryan NM, Birring SS, Gibson PG. Gabapentin for refractory chronic cough: a randomised, double-blind, placebo-controlled trial. Lancet 2012; 380: 1583-1589.

16 Jeyakumar A, Brickman TM, Haben M. Effectiveness of amitriptyline versus cough suppressants in the treatment of chronic cough resulting from postviral vagal neuropathy. Laryngoscope 2006; 116: 2108-2112.

17 Vertigan AE, Kapela SL, Ryan NM, et al. Pregabalin and speech pathology combination therapy for refractory chronic cough: a randomized controlled trial. Chest 2016; 149: 639-648.

18 Vertigan AE, Theodoros DG, Gibson PG, et al. Efficacy of speech pathology management for chronic cough: a randomised placebo controlled trial of treatment efficacy. Thorax 2006; 61: 1065-1069.

19 Chamberlain Mitchell SA, Garrod R, Clark L, et al. Physiotherapy, and speech and language therapy intervention for patients with refractory chronic cough: a multicentre randomised control trial. Thorax 2016; 72: 129-136.

20 West PW, Canning BJ, Merlo-Pich E, et al. Morphologic characterization of nerves in whole-mount airway biopsies. Am J Respir Crit Care Med 2015; 192: 30-39.

21 HOLTON P. The liberation of adenosine triphosphate on antidromic stimulation of sensory nerves. J Physiol 1959; 145: 494-504.

22 Chen CC, Akopian AN, Sivilotti L, et al. A P2X purinoceptor expressed by a subset of sensory neurons. Nature 1995; 377: 428-431.

23 Ford AP, Undem BJ. The therapeutic promise of ATP antagonism at P2X3 receptors in respiratory and urological disorders. Front Cell Neurosci 2013; 7: 267.

24 Abdulqawi R, Dockry R, Holt K, et al. P2X3 receptor antagonist (AF-219) in refractory chronic cough: a randomised, double-blind, placebo-controlled phase 2 study. Lancet 2015; 385: 1198-1205.

25 Fowles HE, Rowland T, Wright $\mathrm{C}$, et al. Tussive challenge with ATP and AMP: does it reveal cough hypersensitivity? Eur Respir J 2017; 49: 1601452.

26 Basoglu OK, Pelleg A, Essilfie-Quaye S, et al. Effects of aerosolized adenosine 5'-triphosphate vs adenosine $5^{\prime}$-monophosphate on dyspnea and airway caliber in healthy nonsmokers and patients with asthma. Chest 2005; 128: 1905-1909.

27 Bonvini SJ, Birrell MA, Grace MS, et al. Transient receptor potential cation channel, subfamily V, member 4 and airway sensory afferent activation: role of adenosine triphosphate. J Allergy Clin Immunol 2016; 138: 249-261. 
28 Birrell MA, Belvisi MG, Grace M, et al. TRPA1 agonists evoke coughing in guinea pig and human volunteers. Am J Respir Crit Care Med 2009; 180: 1042-1047.

29 Widdicombe J, Eccles R, Fontana G. Supramedullary influences on cough. Respir Physiol Neurobiol 2006; 152: 320-328.

30 Davenport PW. Urge-to-cough: what can it teach us about cough? Lung 2008; 186: Suppl. 1, S107-S111.

31 Dicpinigaitis PV, Bhat R, Rhoton WA, et al. Effect of viral upper respiratory tract infection on the urge-to-cough sensation. Respir Med 2011; 105: 615-618. 